EGU2020-13490, updated on 26 May 2020

https://doi.org/10.5194/egusphere-egu2020-13490

EGU General Assembly 2020

(c) Author(s) 2020. This work is distributed under

the Creative Commons Attribution 4.0 License.

\title{
Emissions from natural gas and oil operations: The airborne METHANE-To-Go field campaign in the Persian/Arabian Gulf region
}

\author{
Heidi Huntrieser ${ }^{1}$, Anke Roiger ${ }^{1}$, Daniel Sauer ${ }^{1}$, Hans Schlager ${ }^{1}$, Mariano Mertens ${ }^{1}$, and Stefan \\ Schwietzke ${ }^{2}$ \\ ${ }^{1}$ DLR-Oberpfaffenhofen, Wessling, Germany (heidi.huntrieser@dlr.de) \\ ${ }^{2}$ Climate and Energy, Environmental Defense Fund (EDF), Berlin, Germany \& Boulder, CO, USA
}

\begin{abstract}
About $60 \%$ of global methane $\left(\mathrm{CH}_{4}\right)$ emissions are due to human activities. Since the Paris Agreement was signed in 2016, an increasing effort has been devoted to accelerate the greenhouse-gas-emissions mitigation. Afore in 2014, the Oil and Gas Climate Initiative (OGCI) formed, which is an international industry-led organization including 13 member companies from the oil and gas industry, representing $1 / 3$ of the global operated oil and gas production. The Environmental Defense Fund (EDF) and United Nations Environment Programme (UNEP) funded project METHANE-To-Go aims to focus on trace gas emissions from the natural gas and oil operations in the Persian/Arabian Gulf region, a wealthy region which contains about $50 \%$ of the world's oil reserves. The project is coordinated by the Deutsches Zentrum für Luft- und Raumfahrt (DLR) and envisages to carry out airborne in-situ measurements with the German Deutsches Zentrum für Luft- und Raumfahrt (DLR) Falcon-20 in autumn 2020 in cooperation with local OGCl partners.
\end{abstract}

The flaring, venting and combustion processes produce large amounts of $\mathrm{CH}_{4}$, a greenhouse gas that is $\sim 84$ times more potent than $\mathrm{CO}_{2}$ (measured over a 20-year period) and in focus of current mitigation strategies trying to reduce global warming. However, there is a huge lack of detailed $\mathrm{CH}_{4}$ measurements worldwide and especially from the Gulf region. The contribution from this region to the global $\mathrm{CH}_{4}$ mass balance is presently unknown. Furthermore, recently a first global satellite-derived $\mathrm{SO}_{2}$ emissions inventory was established based on measurements with the Ozone Monitoring Instrument (OMI) on the NASA Aura satellite showing a number of $\mathrm{SO}_{2}$ hot spots in the Persian/Arabian Gulf region. The Middle East region was high-lighted as the region with the most missing $\mathrm{SO}_{2}$ sources compared to reported sources in the global emission inventories. The petroleum industry operations are mainly responsible for these emissions, since high amounts of $\mathrm{H}_{2} \mathrm{~S}$ are trapped in oil and gas deposits and released during extraction. In recent years, the air quality in this region has worsened dramatically and concurrently global warming is especially strong.

The DLR Institute of Atmospheric Physics plan the performance of airborne in-situ measurements to probe the isolated, outstanding emission plumes from the different $\mathrm{CH}_{4}$ and $\mathrm{SO}_{2}$ sources in the southern part of the Gulf region as mentioned above. A novel dual Quantum Cascade Laser (QCL) 
instrument based on laser absorption spectroscopy will be deployed to measure $\mathrm{CH}_{4}$ and $\mathrm{CO}$, and related trace gases as $\mathrm{CO}_{2}$ and $\mathrm{C}_{2} \mathrm{H}_{6}$, which can be used to distinguish between different $\mathrm{CH}_{4}$ sources (flaring, venting and combustion). An ion-trap chemical ionization mass spectrometer (ITCIMS) is foreseen for the measurements of $\mathrm{SO}_{2}$. Both instruments operate with a high precision/accuracy and a temporal resolution of 0.5 to $1 \mathrm{~s}$, which covers a horizontal distance of roughly 50-200 m during the flight. Measurements of further trace species are also foreseen (e.g. $\mathrm{NO}, \mathrm{NO}_{\mathrm{y}}$, and aerosols) and simulations with particle dispersion models for flight planning and post analyses (HYSPLIT and the EMAC related model MECO(n)). Furthermore, satellite validation is envisaged with the TROPOMI instrument on Sentinel-5P (focus on $\mathrm{CH}_{4}$ and $\mathrm{SO}_{2}$ ). 